\title{
Condrosarcoma Mesenquimal Sinonasal Grado Tres y Carcinosarcoma de Glándula Mamaria de un Canino. Estudios Clínico e Histopatológico
}

\author{
Sinunasal Mesenchymal Chondrosarcoma Grade 3 and Mammary Gland \\ Carcinosarcoma of Canine. Clinical and Histopathology Study \\ "Anita Roque Rodríguez; **Julieta Ochoa Amaya \& ***July Narváez Cancimansi
}

ROQUE, R. A. I.; OCHOA, A. J. E. \& NARVAEZ, C. J. Condrosarcoma mesenquimal sinonasal grado tres y carcinosarcoma de glándula mamaria de un canino. Estudios clínico e histopatológico. Int. J. Morphol., 26(4):861-875, 2008.

RESUMEN: A la Clínica Veterinaria de la Universidad de los Llanos, llegó un canino hembra de 9 años de edad raza Chow Chow, cuyo motivo de consulta fue epistaxis bilateral 4 meses atrás y una masa en la región nasal. Según lo reportado por el propietario, la masa había comenzado a salir 1 mes atrás del día de la consulta. Al examen clínico presentaba una masa subdérmica en la región nasal superior de $2 \mathrm{~cm}$ de diámetro. Se realizó una citología de la misma y se encontraron células inflamatorias sin presencia de células neoplásicas. El paciente volvió al mes y la masa con un diámetro de $5 \mathrm{~cm}$, estaba ubicada en la región nasal superior y región zigomática. El can presentaba disnea, anorexia, deshidratación del 6\%, secreción mucopurulenta nasal y ocular, midriasis bilateral, reflejo corneal bilateral negativo, aumento de la presión intraocular del ojo derecho. En la glándula mamaria inguinal derecha presentaba una masa de $2 \mathrm{~cm}$ de diámetro dura y móvil. Se realizó una citología por aspirado con aguja fina, de distintas zonas de las masas, tanto de la nariz, como de la glándula mamaria. Se valoró la citología permitiéndose definir el origen tumoral del proceso. Se realizó biopsia por incisión de la región sinonasal, diagnosticándose tumor mesenquimal maligno grado tres condrosarcoma sinonasal, conformado por células cartilaginosas pleomórficas con anisocariosis. Se realizaron radiografías de la región nasal y del pulmón, encontrándose una zona radiopaca a nivel del seno maxilar con osteolisis del hueso, se evidenciaba la masa de aproximadamente $4 \mathrm{~cm}$ de ancho por $2 \mathrm{~cm}$ de largo en el lado derecho. En el pulmón no se evidenció metástasis. Después del diagnóstico de histopatología se decide realizar la eutanasia, encontrándose histopatológicamente metástasis en pulmón, confirmación del condrosarcoma mesenquimal y un carcinosarcoma de glándula mamaria.

PALABRAS CLAVE: Canino; Condrosarcoma sinonasal; Carcinosarcoma de glándula mamaria.

\section{INTRODUCCIÓN}

El condrosarcoma (CS) es un tumor maligno, en el cual las células producen una matriz condroide y fibrilar neoplásica, pero nunca sintetizan de manera directa osteoide o hueso canceroso (Goldschmidt \& Thrall, 1985). Sin embargo, Carlyle et al. (1997) reportan que la matriz ósea puede ser producida en los condrosarcomas y usualmente se originan de algunos mecanismos reactivos o metaplásicos. Carlyle et al. y Fernández et al. (2005) referencian a los condrosarcomas como una de las neoplasias de origen osteogénico más frecuentes en la especie canina, que suelen aparecer en animales de edad avanzada y, aunque no producen metástasis, son tumores localmente agresivos y osteolíticos, presentando así un mal pronóstico. Stayler et al., 1994, reportan que el condrosarcoma puede originarse de la cavidad medular (central) o periostio (periférico), siendo más común el de origen medular.
El condrosarcoma es la neoplasia sinonasal no epitelial más común en el perro y las metástasis son consideradas raras (Hahn et al., 1997; Fernández et al.). Es un tumor maligno caracterizado por células tumorales que producen cartílago en el hueso. La localización más común del condrosarcoma en el perro, corresponde a las uniones costocondrales en la unión de las costillas, cavidad nasal y la pelvis (Stayler et al.; Brodey et al., 1963). Ocurren más frecuentemente en huesos planos de razas de perros grandes pero son capaces de originarse en otras razas y otras localizaciones (Stayler et al.). Hahn et al. corroboran lo afirmado por Stayler et al. sobre el origen del CS, el cual es visto en número equivalente en áreas nasales y nasofrontales, siendo estos tumores comúnmente bilaterales. Ellos reportan que la tasa metastásica de CS nasal en los perros es del $15 \%$. De las 27 necropsias realizadas en perros con un diagnóstico de 
CS nasal, 4 tuvieron metástasis, todos comprometiendo los pulmones. No ha sido reportado la metástasis a nódulos linfoides (Hahn et al.). Igualmente con los reportes de Hahn et al.; Ohta et al., 2004), coinciden en que el CS en la cavidad nasal es el sitio más común en los perros y es menos asociado con metástasis que el CS de origen no sinonasal como lo es el esqueleto. El CS comprende aproximadamente el $10 \%$ de los tumores de hueso primario de los perros, siendo éste el segundo tumor primario óseo y de cartílago más común (De Buen de Arguero, 2001), que representa el 5 al $10 \%$, según lo reportado por Dernell et al. (Ohta et al.). Ling et al. (1974), Brodey et al. (1963) y Stayler et al. comparan entre sí a osteosarcomas y condrosarcomas, siendo éstos últimos los que producen menos metástasis y presenta un mayor intervalo de vida después de aparecer los signos clínicos.

La edad principal de inicio de los signos clínicos es aproximadamente a los 7 años de edad, no hay predilección por sexo (Yildiz et al., 2003; Hahn et al.) o raza (Yildiz et al.). Aunque De Buen de Arguero, hace referencia a que es mayor la predilección de presentación del CS en los perros de la raza bóxer. Una revisión de los condrosarcomas reveló una edad mediana de afectación de 6 años sin predilección sexual (Brodey et al., 1963). Como signos clínicos del condrosarcoma se manifiestan estornudos, epixtasis e hinchazón nasal (Newton \& Siemering, 1983; Hahn et al.).

Por citología el CS, cuando es bien diferenciado, los frotis se componen de condrocitos, que son células pequeñas, redondas a poliédricas con abundante citoplasma claro finamente vacuolado, núcleo grande oval, y nucléolo poco evidente. Es frecuente encontrar binucleación y escasas mitosis atípicas, estas células se encuentran mezcladas con material de aspecto mixoide, y el fondo del frotis presenta una apariencia fibrilar o granular (De Buen de Arguero; Fernández et al.).

Histológicamente, el CS es una neoplasia maligna en la cual las células tumorales producen cantidades variables de condroide neoplásico y matriz fibrilar pero no osteoide (Goldschmidt \& Thrall.; Stayler et al.; Ohta et al.). El condrosarcoma mesenquimal, es un tipo variante de CS, es caracterizado por una apariencia transicional, con elementos de ambos, como las células mesenquimales indiferenciadas y una selección de componentes condroides diferenciados (Ohta et al.). El CS mesenquimal es reportado en perros en la región sinonasal, lo mismo que se origina de sitios donde existe cartílago normal, tales como los cartílagos costales, cartílago escapular, pelvis, turbinatos y septum nasales (Carlyle et al.; Meuten, 2002; Hahn et al.). No presenta metástasis en sitios lejanos al origen. Hay destrucción extensa y reemplazo de tejido nasofrontal (Meuten).
Contiene poco estroma densamente empaquetado y predominantemente se pueden encontrar células spindle (Meuten) primitivas a células estromales mesenquimales ovoides (Carlyle et al.). Hahn et al. reportan metástasis renal bilateral de condrosarcoma nasal en un perro, igualmente Carlyle et al. concuerdan en que el CS invade el organismo haciendo metástasis a pulmones y a otro lugares.

Meuten cita unas características de malignidad para el CS, como son las células abundantes con núcleo basófilo, presencia de células cartilaginosas grandes con núcleos simples o múltiples de heterocromatina, los cuales son prominentes e irregulares; adicionalmente Carlyle et al. describe características diagnósticas de malignidad de las células del condrosarcoma como son núcleos hipercromáticos, nucléolo eosinofílico grande y nucléolos agrandados múltiples, siendo una de las principales características del CS, la desorganización celular.

Además, Meuten reporta que las figuras mitóticas no son frecuentes en condrosarcomas bien diferenciados, una simple figura mitótica soporta el diagnóstico de malignidad, aunque los CS no diferenciados poseen alto número de figuras mitóticas. Hahn et al. reportan que tanto tumores primarios y metastáticos fueron identificados como condrosarcomas grado 3 y presentaron un índice mitótico bajo $(<1$ por campo).

Según Meuten, los condrosarcomas pueden ser clasificados por su gradación, en:

Grado 1. Células uniformes binucleadas sin figuras mitóticas. Grado 2. Las células del cartílago son pleomórficas pero no presentan áreas indiferenciadas, poseen un número moderado de figuras mitóticas. Pueden presentarse figuras mitóticas y metástasis.

Grado 3. Área de sarcoma indiferenciado. Con núcleos pleomórficos marcados, figuras mitóticas numerosas. Puede hacer metástasis pulmonar.

Los tumores mamarios son neoplasias que se presentan comúnmente en varias especies, incluyendo caninos, roedores y humanos. Se han encontrado rutinariamente en la práctica clínica y constituyen la neoplasia más frecuente en caninos, representando de un $25 \%$ a un $50 \%$ de todas las neoplasias en hembras caninas. (Theilen \& Madewell,1979; Giraldo et al., 2003). Los tumores mamarios pueden ser benignos, sin embargo, el $40 \%$ o $50 \%$ de éstos son malignos. La clasificación de estos tumores por la Organización Mundial de la Salud fue basada en morfología descriptiva y combina la histogénesis, la clasificación o descripción morfológica y el pronóstico que se asocia a una serie de características histológicas relacionadas con un incremento de 
malignidad (OMS, 1999; Misdorp et al., 1999; Giraldo et al.). Las neoplasias de la glándula mamaria se originan de células de revestimiento epitelial, ductal o alveolar, de células mioepiteliales o del tejido conectivo intersticial. Sin embargo, se pueden presentar neoplasias mixtas que contienen tejido epitelial o mioepitelial con áreas de tejido cartilaginoso, óseo y algunas pocas compuestas sólo de tejido mesenquimal (Giraldo et al.)

El carcinosarcoma de glándula mamaria es un tumor compuesto de células que morfológicamente reensamblan componentes epiteliales malignos (luminar y/o mioepiteliales) y células perteneciente a elementos de tejido conectivo maligno, hueso o cartílago. Este último componente se origina de focos metaplásicos del componente epitelial o del estroma. Los tumores mixtos malignos tienen un mal pronóstico y hacen metástasis en el primer año de desarrollo puede reconocerse la mezcla de los dos tipos de componentes carcinomatosos y sarcomatosos. Las metástasis son mixtas, sarcomatosas o carcinomatosas. Como un carcinoma complejo, la sobrevivencia post quirúrgica es relativamente larga, en promedio 18 meses (Meuten). Ese tipo de tumor no es común en el perro y extremadamente raro en el gato (Misdorp et al.; Meuten). El riesgo de desarrollar neoplasia mamaria se incrementa en ciertas razas caninas, lo cual a su vez sugiere un componente genético. Las razas citadas por los autores varían de acuerdo al estudio y a la localización geográfica. Sin embargo, las razas que aparecen con mayor frecuencia en los diferentes reportes incluyen: Poodle (toy y miniatura), Springer Spaniels, Cocker Spaniels, English Setter, Pointers, Pastor Alemán, Maltes, Yorkshire Terriers y Dachshunds (Sorenmo, 2003).

\section{HISTORIA CLINICA}

A la Clínica Veterinaria de la Escuela de Medicina Veterinaria y Zootecnia de la Facultad de Ciencias Agropecuarias y Recursos Naturales de la Universidad de los Llanos, fue ingresado un canino hembra de 9 años de edad raza Chow Chow, cuyo motivo de consulta fue epistaxis bilateral 4 meses atrás y una masa en la región nasal. Según lo reportado por el propietario, la masa había comenzado a salir 1 mes atrás del día de la consulta. Al examen clínico presentaba una masa subdérmica en la región nasal superior de $2 \mathrm{~cm}$ de diámetro. Se realizó una citología de la misma y se encontraron células inflamatorias sin presencia de células neoplásicas. El paciente volvió al mes y la masa presentaba un diámetro de $5 \mathrm{~cm}$, era de consistencia blanda, ubicada en la región nasal superior y región zigomática. El paciente presentaba disnea, anorexia, deshidratación del 6\%, pelo hirsuto, opaco, secreción mucopurulenta nasal y ocu- lar, midriasis bilateral, reflejo corneal bilateral negativo, aumento de la presión intraocular del ojo derecho. La prueba de obstáculos realizada en el consultorio fue negativa, lo cual mostró una pérdida total de la visión. En la glándula mamaria inguinal derecha presentaba una masa de $2 \mathrm{~cm}$ de diámetro dura y móvil.

En el cuadro hemático se obtuvieron los siguientes resultados: Hematocrito de $38 \%$ (35-57\%), hemoglobina $12,6(11,9-18,9 \mathrm{~g} / 100 \mathrm{ml})$, leucocitos de $14000(6-18 \mathrm{x}$ 103), neutrófilos $94(60-77 \%)$, linfocitos $4(12-30 \%)$, monocitos $1(3-10 \%)$, eosinófilos $1(2-10 \%)$, recuento de glóbulos rojos $6238500\left(5,5-9.5 \times 10^{6}\right)$ y trombocitos $216300\left(200-500 \times 10^{3}\right)$.

Se tomó una muestra para química sanguínea, donde se evaluó BUN, creatinina, ALT y AST, los resultados fueron los siguientes:

\begin{tabular}{lcc} 
& Paciente & \multicolumn{1}{c}{ Valor de Referencia } \\
BUN: & $17,8 \mathrm{mg} / \mathrm{dl}$ & $10-28 \mathrm{mg} / \mathrm{dl}$ \\
Creatinina: & $0,8 \mathrm{mg} / \mathrm{dl}$ & $0,5-1,5 \mathrm{mg} / \mathrm{dl}$ \\
ALT: & $35,5 \mathrm{U} / \mathrm{L}$ & $21-102 \mathrm{U} / \mathrm{L}$ \\
AST: & $97,7 \mathrm{U} / \mathrm{L}$ & $23-66 \mathrm{U} / \mathrm{L}$
\end{tabular}

De la masa encontrada en la región nasal se realizó una citología por aspiración con aguja fina, obteniéndose un material muco sanguinolento, del cual se realizaron láminas que se enviaron al Laboratorio de Patología de la Universidad de los Llanos. En este análisis se reportó una gran cantidad de células sanguíneas y no se observó ninguna célula neoplásica. También se enviaron muestras al Laboratorio de Microbiología de la Universidad de los Llanos, de la muestra obtenida por citología, para realizar cultivos para hongos y antibiograma. Esperando los resultados de microbiología, se cita al paciente en 3 días para realizar un tratamiento específico. Se envía un tratamiento paliativo, el cual no incluye antibiótico ni antimicótico, ya que se esperan los resultados del laboratorio. Dentro de los diagnósticos diferenciales se citaron: tumor venéreo transmisible, condrosarcoma, osteosarcoma, rinosporidium, blastomicosis, criptococosis, pólipo nasal y glaucoma.

El propietario no trae al paciente a control y vuelve al mes. Se observa entonces que la masa aumentó dos veces su tamaño inicial, ahora mide aproximadamente $5 \mathrm{~cm}$ de diámetro, está ubicada en la región nasal superior y cigomática del lado derecho, era de consistencia dura y compromete el órgano de la visión del mismo lado. En él se observa queratocono, queratoconjuntivitis, miosis, protusión del bulbo ocular y del tercer párpado y presenta una secreción mucopurulenta; en el bulbo ocular izquierdo se tiene midriasis y reflejo corneal negativo. El paciente se encuentra muy deprimido, con un tiempo de llenado capilar de 3 
segundos, condición corporal 2 de 5, secreción nasal bilateral sanguinopurulenta, disnea severa. Se observó, a nivel del paladar duro, una masa de $3 \mathrm{~cm}$ de largo por $2 \mathrm{~cm}$ de ancho, al lado derecho, dura e inmóvil. El canino superior derecho tenía un contenido sanguinolento y al presionar la encía de ese lado, salía una secreción sanguinopurulenta. En la glándula mamaria inguinal izquierda se encontró una masa aproximadamente de $3 \mathrm{~cm}$ de diámetro, dura, lobulada y poco móvil. El propietario reporta que la perra está muy deprimida y presenta anorexia desde hace 4 días.

Se realizó nuevamente un cuadro hemático, BUN, creatinina, ALT, AST, fosfatasa alcalina, proteínas plasmáticas totales, albúmina y globulina. Los resultados obtenidos fueron:

Hematocrito 25\% (35 - 57\%), Hemoglobina 6,5 (11,9 $18,9 \mathrm{~g} / 100 \mathrm{ml})$, Leucocitos $8450\left(6-18 \times 10^{3}\right)$, neutrófilos $87(60-77 \%)$, linfocitos $8(12-30 \%)$, monocitos 2 (3 $10 \%)$, eosinófilos $3(2-10 \%)$, recuento de glóbulos rojos $4.390 .000\left(5,5-9,5 \times 10^{6}\right)$ y trombocitos $291900(200-$ $\left.500 \times 10^{3}\right)$.

$\begin{array}{lll} & \text { Paciente } & \text { Valor de Referencia } \\ \text { BUN: } & 8,8 \mathrm{mg} / \mathrm{dl} & 10-28 \mathrm{mg} / \mathrm{dl} \\ \text { Creatinina: } & 0,8 \mathrm{mg} / \mathrm{dl} & 0,8 \mathrm{mg} / \mathrm{dl} \\ \text { ALT: } & 22 \mathrm{U} / \mathrm{L} & 21-102 \mathrm{U} / \mathrm{L} \\ \text { AST: } & 861 \mathrm{U} / \mathrm{L} & 23-66 \mathrm{U} / \mathrm{L} \\ \text { F.A: } & 60 \mathrm{U} / \mathrm{L} & 10-73 \mathrm{U} / \mathrm{L} \\ \text { P.P.T: } & 4,55 \mathrm{~g} / \mathrm{dl} & 5,4-7,1 \mathrm{~g} / \mathrm{dl} \\ \text { Albúmina } & 1,99 \mathrm{~g} / \mathrm{dl} & 2,5-3,6 \mathrm{~g} / \mathrm{dl} \\ \text { Globulina } & 2,55 \mathrm{~g} / \mathrm{dl} & 2,4-4 \mathrm{~g} / \mathrm{dl}\end{array}$

Se realizó un examen radiográfico, una biopsia por insición y una citología por aspiración con aguja fina Se procedió a estabilizar al paciente con el siguiente tratamiento: Líquidos intravenosos (solución salina $0,9 \%$ con Dextromin, el cual contiene glucosa, aminoácidos y vitaminas), Cefaxona (es ceftriaxona, una cefalosporina de tercera generación) se administro vía intravenosa cada 12 horas, complejo B y Ferrex (sulfato ferroso) cada 24 horas vía intramuscular, Finadyne vía intramuscular cada 12 horas, Quercetol vía intravenosa cada 24 horas. El pronóstico del paciente es reservado.

Examen radiográfico. Se procedió a tomar dos radiografías, en la posición latero-lateral, se observó una zona radiopaca a nivel del seno maxilar con osteolisis del hueso premaxilar (Fig 1A), en la posición ventrodorsal, se encontró lisis del hueso premaxilar a nivel del segundo premolar del lado derecho, una zona radiopaca a nivel del seno maxilar de aproximadamente $4 \mathrm{~cm}$ de ancho por $2 \mathrm{~cm}$ de largo (Fig 1B), evidenciándose una masa a nivel del seno maxilar derecho.
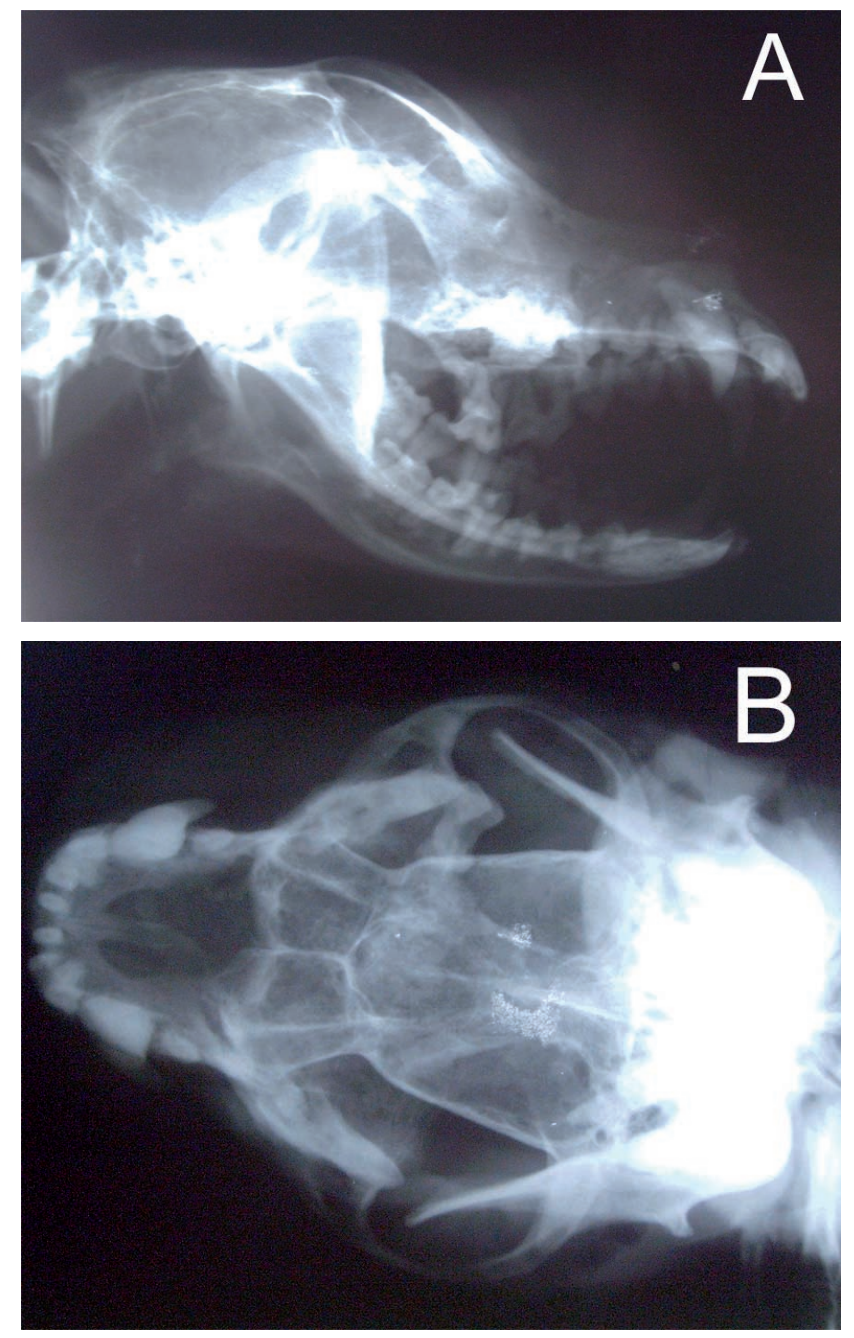

Fig. 1. Radiografía en proyección latero-lateral con evidencia de una zona radiopaca en el seno maxilar a nivel del tercer premolar al tercer molar, con osteolisis del hueso premaxilar a nivel del segundo y tercer premolar (A). En la proyección dorso-ventral se encontró lisis del hueso premaxilar a nivel del segundo premolar del lado derecho, una zona radiopaca a nivel del seno maxilar de aproximadamente $4 \mathrm{~cm}$ de ancho por $2 \mathrm{~cm}$ de largo (B).

Citología por aspiración con aguja fina. Tanto en la neoplasia de la nariz y de la glándula mamaria se encontró una elevada celularidad de una población de células de estirpe conjuntiva con núcleo redondo u ovalado, citoplasma basófilo con finas vacuolas y dispuestas en voluminosos agregados celulares y rodeados por una matriz amorfa extra e intercelular eosinofílica, muy común en neoplasias de origen óseo/cartilaginoso.

La glándula mamaria, se encontró compuesta por una elevada celularidad de una población de células con anisocitosis y anisocariosis, elevada basofilia en la cromatina y una alta relación núcleo: citoplasma $(\mathrm{N}$ : $\mathrm{C})$, con núcleo 

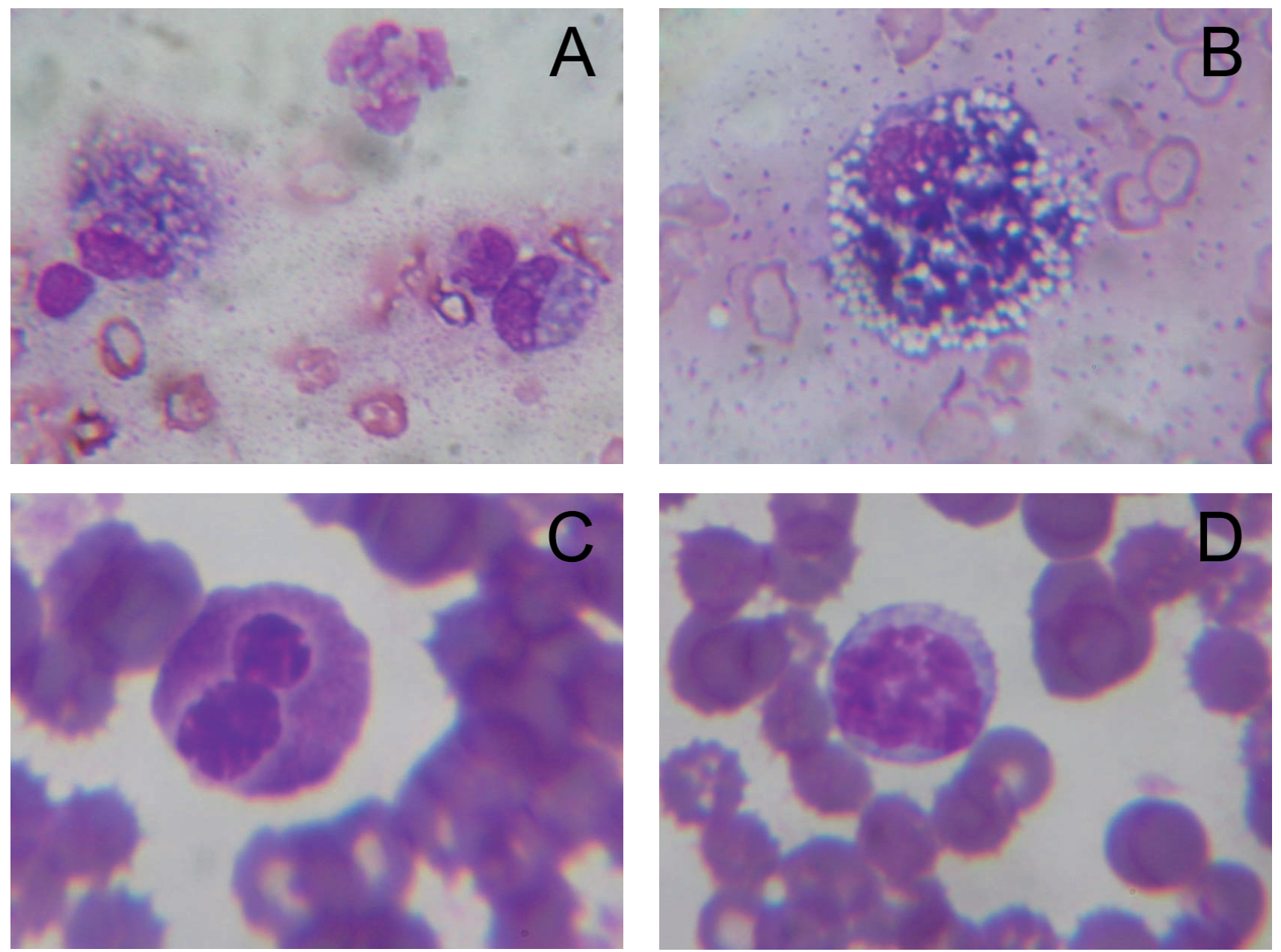

Fig. 2. Citología por aspiración de Glándula mamaria, 40 x. Células con núcleo redondo, citoplasma basófilo con finas vacuolas rodeada por una matriz amorfa extra e intercelular eosinofílica, (A-B). Célula condrocítica maligna con binucleación y nucleolos prominentes, característicos del condrosarcoma, (C). Célula osteoblástica maligna con mitosis atípica, (D).

redondo u ovalado, citoplasma basófilo con finas vacuolas y dispuestas en voluminosos agregados celulares y rodeados por una matriz amorfa extra e intercelular, eosinofílicas (Figs. 2A y 2B). Se encontró binucleación (Fig. 2C) y célula osteoblástica con figuras mitóticas atípicas (Fig. 2D).

De la biopsia por incisión realizada de la neoplasia de la región sinonasal se diagnosticó tumor mesenquimal maligno "Condrosarcoma sinonasal" que compromete hueso; conformado por células cartilaginosas pleomórficas con núcleos prominentes e irregulares con binucleación y anisocariosis nuclear marcada. Presenta zonas hemorrágicas y poco estroma con células de apariencia morfológica celular spindle.

Histopatología de la biopsia por insición. En la neoplasia en la región sinonasal, se encontró tejido conformado por células cartilaginosas largas con núcleos prominentes e irre- gulares, con zonas hemorrágicas (Fig.3A). Población de células condrocíticas pleomórficas (Fig. 3B), con binucleación (Fig. 3C) y con áreas donde las células tienen anisocariosis marcada y núcleos irregulares (Fig. 3D).

Al recibir el diagnóstico de histopatología el cual fue condrosarcoma mesenquimal con un alto grado de malignidad, el pronóstico del paciente pasa de ser desfavorable a reservado, por lo tanto se decide realizar la eutanasia.

Se envió el cadáver al Laboratorio de Patología de la Escuela de Medicina Veterinaria y Zootecnia de la Facultad de Ciencias Agropecuarias y Recursos Naturales de la Universidad de los Llanos, para la realización de la necropsia. Después de realizada la necropsia se tomaron muestras para histopatología en formalina buferada de las masas neoplásicas de la región sinonasal, de glándula mamaria, pulmón, riñón, hígado y corazón. 

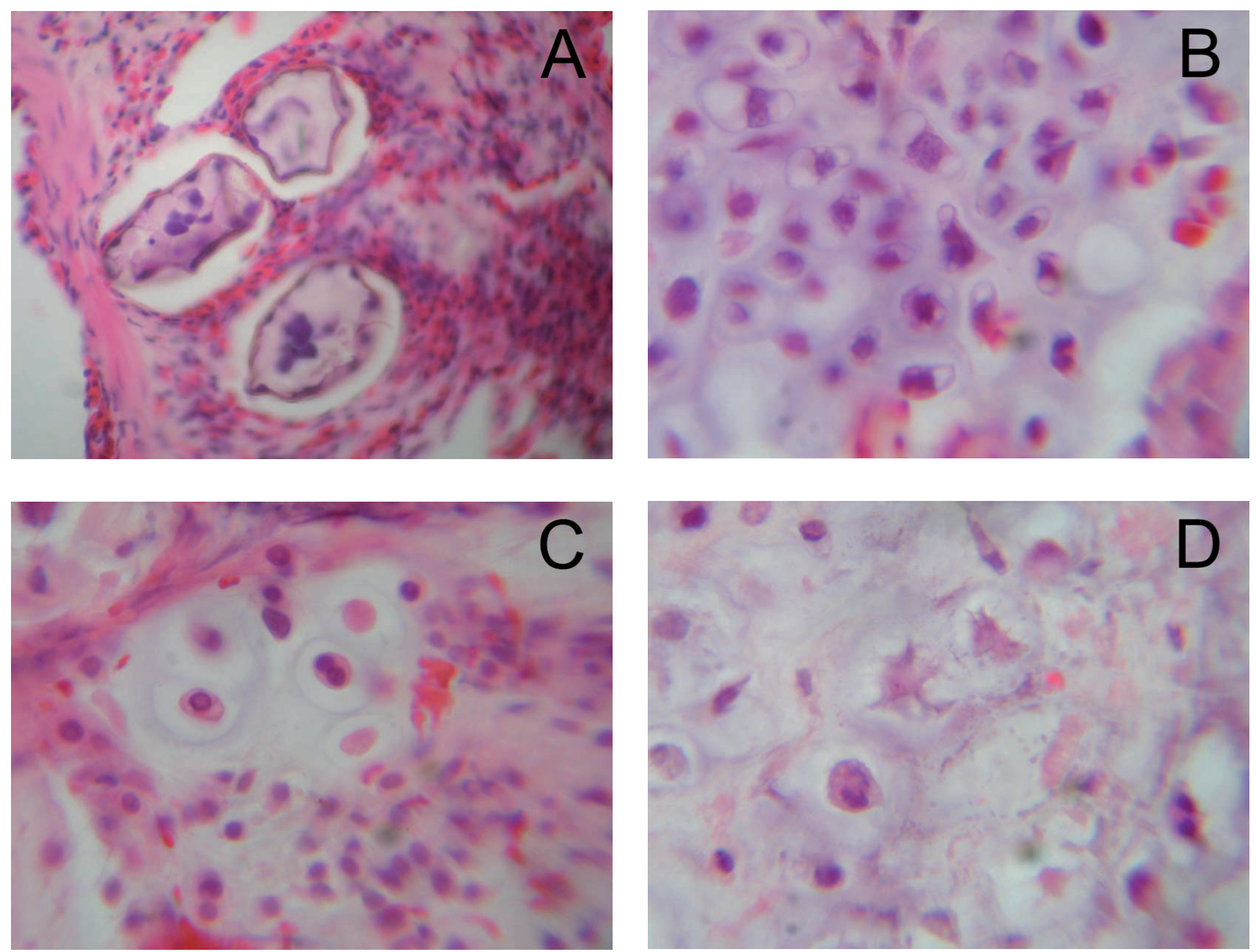

Fig. 3. Células cartilaginosas largas con núcleos prominentes e irregulares, con zonas hemorrágicas (A). Población de células de cartílago pleomórficas. (B) con binucleación, (C) y con áreas donde las células tienen anisocariosis nuclear marcada, núcleos irregulares, (D).

\section{EXAMEN POSTMORTEM}

Hallazgos macroscópicos. Los principales hallazgos a la inspección externa fueron: estado de carnes disminuido, mucosas rosadas, opacidad corneal, pelaje opaco, cavidad oral con placa bacteriana y degeneración de un canino, igualmente se presentaba un aumento del tamaño de la región naso frontal. En el paladar duro aumento del tamaño con dos masas redondeadas. Las tonsilas, aumentadas de tamaño, lo mismo que el músculo masetero.

Se observó mucosa traqueal ligeramente congestionada, los pulmones no colapsaron normalmente después de que el tórax fue abierto, la superficie de corte del pulmón con apariencia carnosa, congestionados, cambios de coloración con zonas de hemorragias, edemas pulmonares y enfisemas en su superficie, se presentaron múltiples masas neoplásicas en los lóbulos pulmonares. En el cora- zón se observó dilatación cardiaca derecha y endocardiosis valvular izquierda o mixomatosis de la válvula atrioventricular izquierda (mitral).

En la región de la glándula mamaria se encontró una masa aproximada de $3 \mathrm{~cm}$ de diámetro, superficie blanca y lobulada, firme al tacto y de consistencia dura al corte con aspecto cartilaginoso y zonas de hemorragia multifocales y necrosis.

Se evidenció invasión tumoral en senos frontales y cavidad orbitaria, con osteolisis de huesos nasales

El diagnóstico presuntivo de necropsia incluyó: condrosarcoma sinonasal con metástasis a pulmones y neoplasia en glándula mamaria. 
Hallazgos microscópicos Todos los tejidos se procesaron con la técnica de rutina de inclusión en parafina con hematoxilina- eosina (H-E). Se procesaron varios cortes de tejido. Los principales hallazgos en la neoplasia encontrada en la glándula mamaria, fueron compatibles con un carcinosarcoma, puesto que se encontraron células fusiformes con escaso tejido conectivo (Fig. 4A y 4B). En la porción glandular (Fig. 4C), las células tienen citoplasma no bien definido. Severa anisocitosis, pleomorfismo celular y nuclear. Los núcleos con cromatina dispuesta en gránulos gruesos distribuida al azar. Algunas células tienden a formarse como células multinucleadas. Presencia de matriz mixoide rica en proteoglicanos. Las células neoplásicas estrechan los acinos reduciendo su luz (Fig. 4C y 4D). Es una neoplasia donde las células tienen los núcleos en diferente posición, unos horizontales y otros verticales (Fig. 5A) y es de tipo infiltrativa in situ (Fig. 5B), su crecimiento es progresivo de tipo papilar ((Fig. 5C). Se aprecian zonas de necrosis e inflamación (Fig. 5D). Presencia de metaplasia cartilaginosa y ósea (Figs. 5E y 5F). Diagnosticándose como un carcinosarcoma de glándula mamaria.

El condrosarcoma sinonasal hizo metástasis pulmonar encontrándose nódulos circunscritos en una cápsula fibrosa compuesta por tejido conjuntivo (Figs. 6A y 6B). La citología pleomórfica que puede apreciarse en los nódulos metastáticos donde se evidenció la malignidad de la neoplasia, compuesto por células con binucleación y con nucléolos; no se aprecian figuras mitóticas, (Figs. 6B y 6C). En el parénquima pulmonar adyacente a los nódulos neoplásicos del condrosarcoma, puede apreciarse otro tipo de neoplasia que ha hecho metástasis al pulmón, el carcinosarcoma de glándula mamaria, (Fig. 6D y 6E); compuesto por células fusiformes tipo spindle, conformando la porción sarcomatosa y componentes adenocarcinomatoso de glándula mamaria de la perra, donde las células con
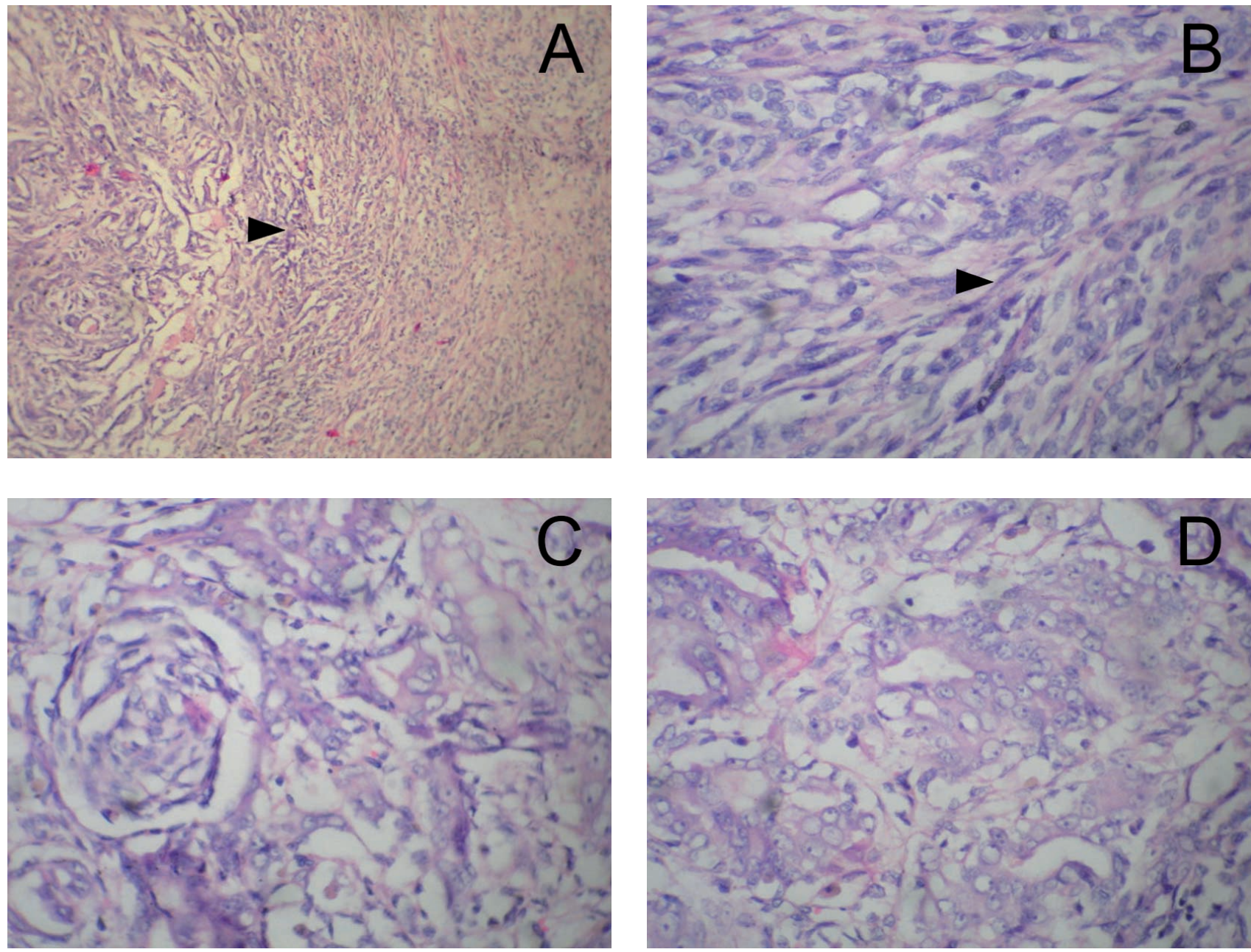

Fig. 4. Carcinosarcoma de Glándula mamaria 10x, y 40x H-E, respectivamente. Parte sarcomatosa formada por células fusiformes o de tipo spindle con escaso tejido conectivo y parte glandular, como lo indica la flecha, (A-B). Acinos glandulares neoplásicos con estratificación del epitelio donde se aprecia el estrechamiento del lumen del acino glandular (C-D). 
núcleos redondos paracentrales adquieren disposición alrededor de un lumen central, con múltiples focos hemorrágicos,
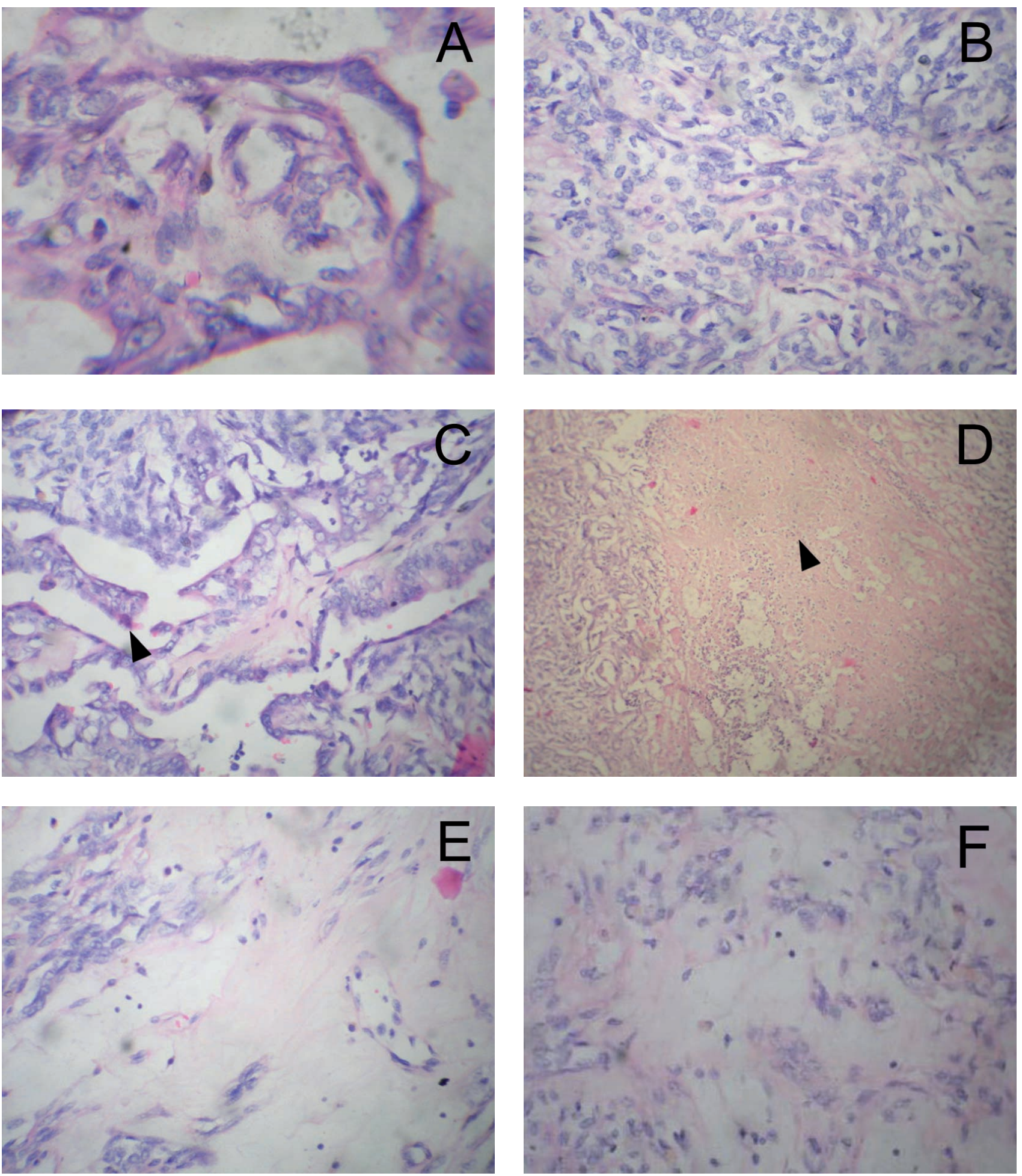

Fig. 5. Carcinosarcoma de glándula mamaria 10x, 40x H-E, respectivamente. Acinos glandulares con pérdida de la polaridad de los núcleos con diferente posición, unos horizontales y otros verticales, (A). Neoplasia infiltrativa in situ. Agresividad de la parte sarcomatosa y glandular (B). Crecimiento proliferativo papilar, (C). Se observa zona de necrosis e infiltrado inflamatorio, (D). Metaplasia cartilaginosa y ósea, (E - F). 

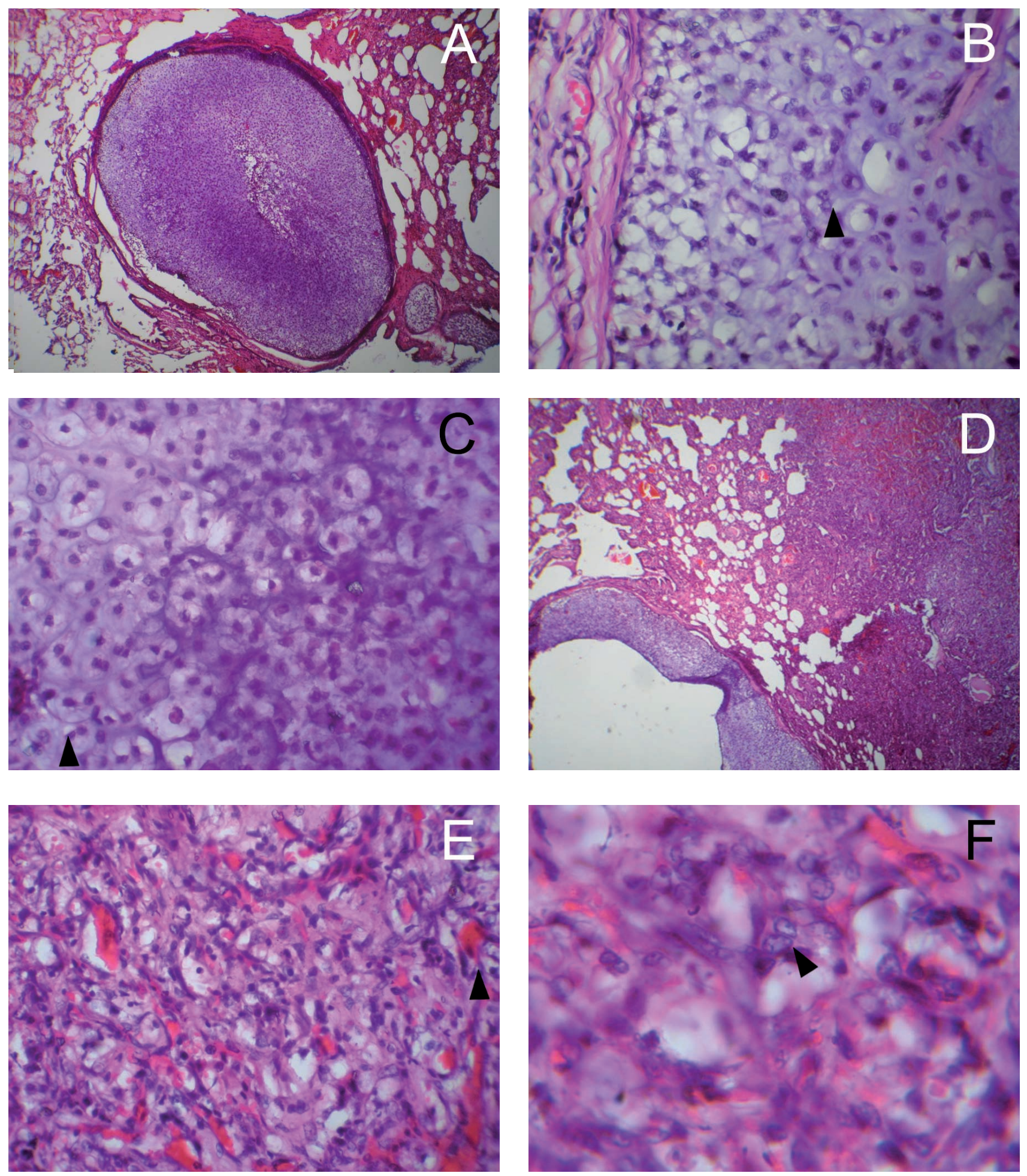

Fig. 6. Nódulos neoplásicos de condrosarcoma en pulmón, delimitados por una cápsula de tejido conectivo, 10x, 40x H-E, respectivamente, (A-B). Área condroide de condrosarcoma diferenciado conformado por células anaplásicas con binucleación, y con nucléolos, (C). Nódulo condroide encapsulado y área no condroide en pulmón, corresponde a metástasis carcinosarcomatosa de glándula mamaria, (D). Metástasis pulmonar de carcinosarcoma de glándula mamaria mostrando células spindle o con forma estrellada, flechas mostrando estructuras vasculares, (E). Células de forma redondeada núcleo paracentral con disposición alrededor de un lumen, (F). 
En la región sinonasal puede apreciarse proliferación de condrocitos en una matriz cartilaginosa (Fig. 7A). Invasión de hueso preexistente por los elementos condroides malignos (Figs. 7 B y 7 C). Invasión en la musculatura estriada de los maseteros por parte de la neoplasia, zonas hemorrágicas,
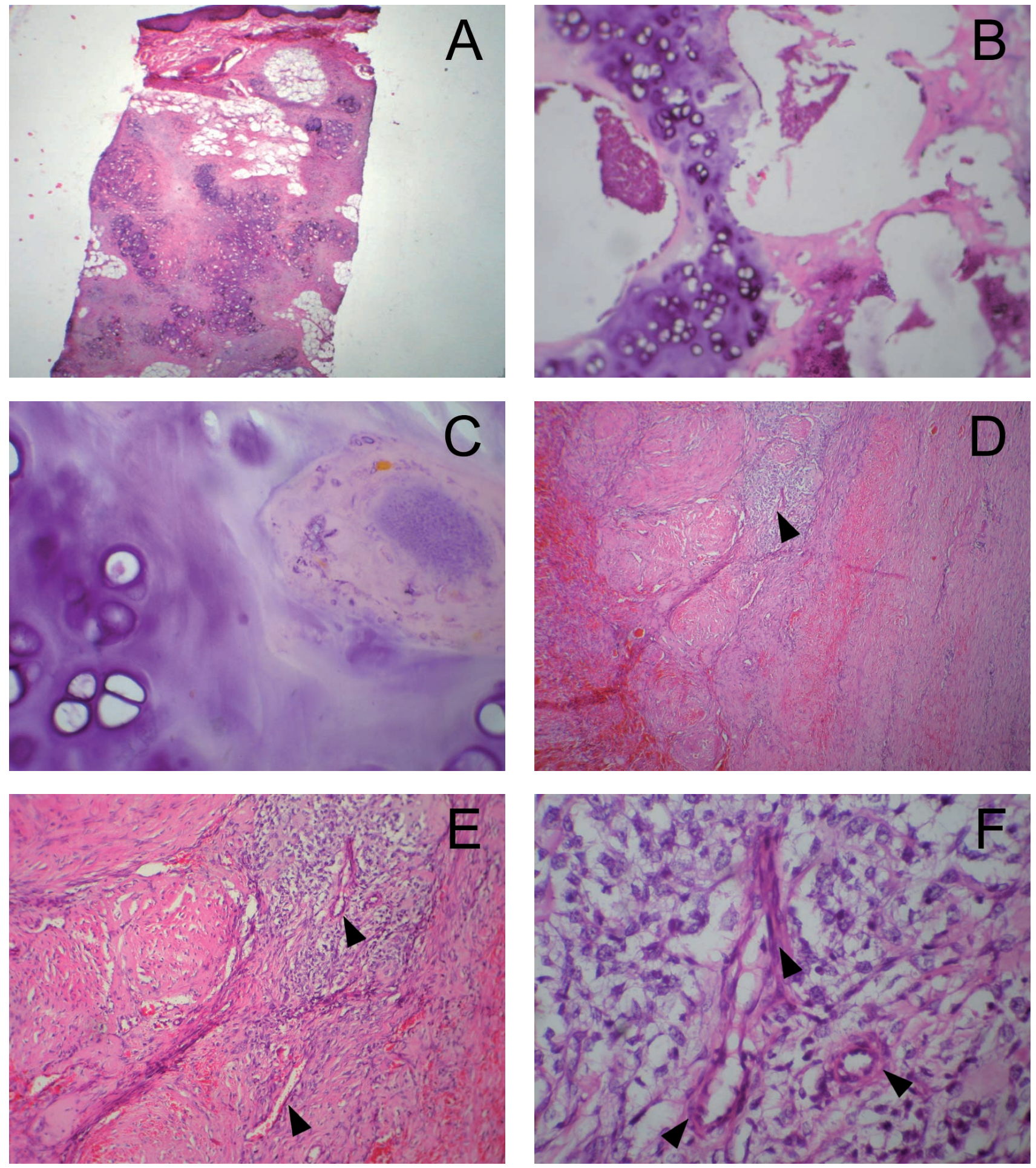

Fig. 7. Sección histológica de la región sinonasal,10x, 40x H-E, respectivamente, (A B). Condrosarcoma con proliferación de condrocitos en una matriz cartilaginosa, (A). Invasión de hueso preexistente por los elementos condroides malignos, (B - C). Invasión en la musculatura estriada de los maseteros por parte de la neoplasia, zonas hemorrágicas (D - E - F). Área anaplasica mixoide de condrosarcoma mesenquimal grado 3, fueron encontradas estructuras vasculares, señaladas con flechas, (D - E - F). Área mixoide en condrosarcoma mesenquimal mostrando células con forma spindle o estrellada, (E - F). 
El hígado presenta esteatosis severa, aumento de la actividad de las células de Kupffer, cambios en los hepatocitos que preceden a la necrosis hepática como son picnosis, cariorrexis, cariolisis; presencia de bilirrubina en el parénquima
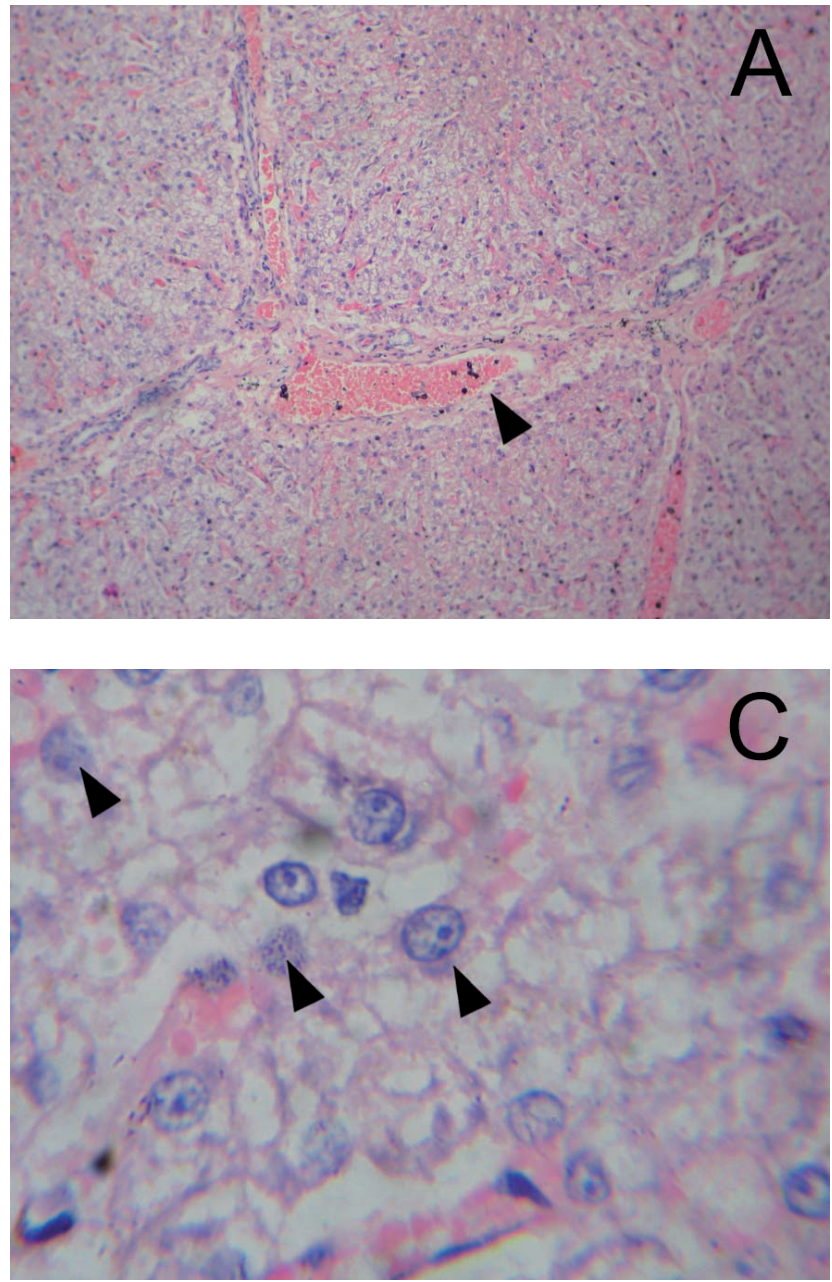

hepático y en las venas portales (Fig. 8A, 8B, 8C). En el riñón se encuentra la pérdida de la albúmina en la luz de los túbulos contorneados, donde aparece de un tono rosa pálido y hemorragias multifocales en la corteza renal (Fig. 8D).
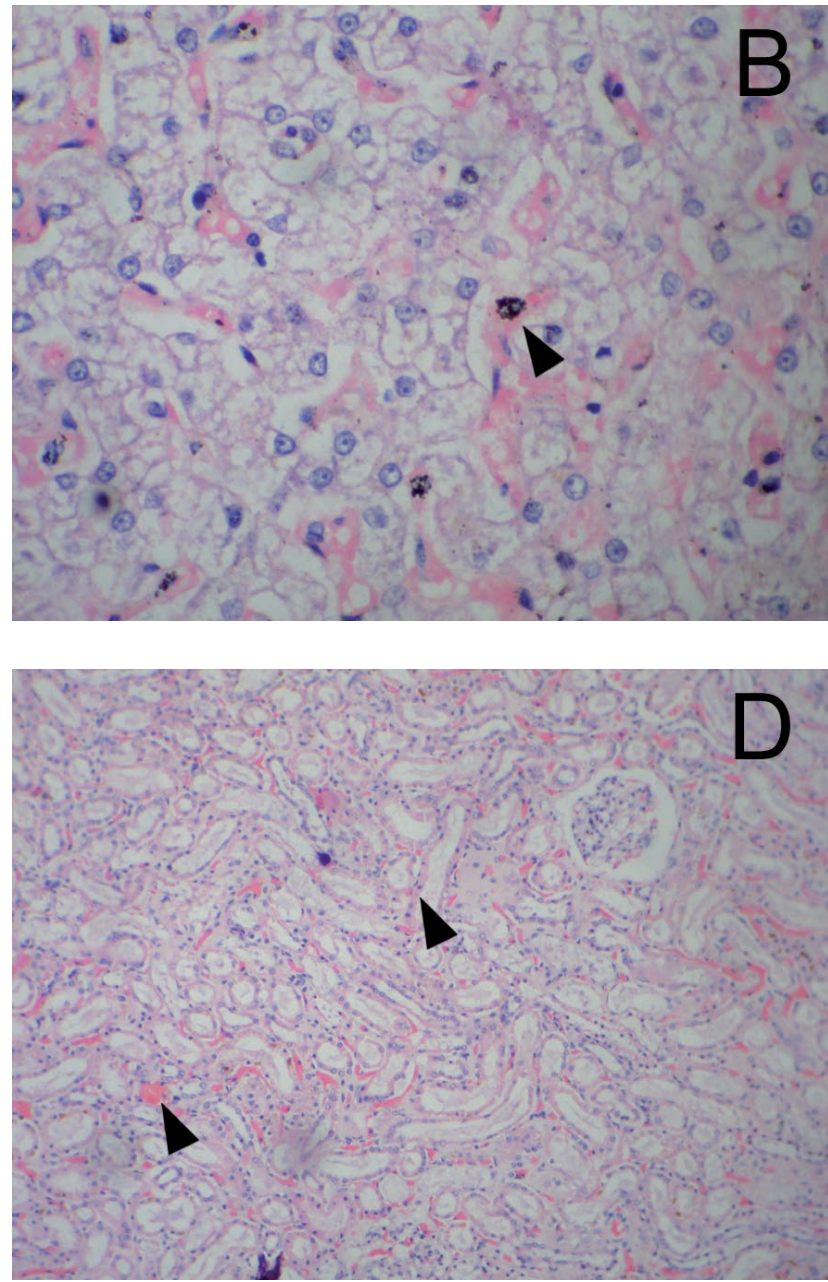

Fig. 8. Sección histológica de la región hepática,10x, 40x H-E, respectivamente, (A - B - C ), y corteza renal, 10 x, H-E, (D). Presencia de bilirrubina en la vena portal y parénquima hepático, (A). Degeneración grasa y picnosis en los núcleos de los hepatocitos, (B - C). Cariorexis y cariolisis en los núcleos de los hepatocitos, (C). Presencia de proteína en la luz tubular renal y hemorragias multifocales en la corteza (D).

\section{DISCUSIÓN}

El paciente durante la observación clínica presentó anemia con hemoglobinemia, neutrofilia y linfopenia con recuento plaquetario normal. Los linfocitos reactivos (inmunocitos o linfocitos transformados) son ocasionalmente encontrados en bajo número en la sangre, durante periodos de estimulación antigénica. Probablemente ellos son linfocitos $\mathrm{T}$ pero podrían ser linfocitos B.

El aumento de la AST, 13 veces por encima de lo normal, se debe al daño muscular (Latimer et al., 2003; Robinson \& Huxtable, 1993; Doxey, 1983) de la región nasal y cigomática, posiblemente por el rápido crecimiento neoplásico. Igualmente cuando hay insuficiencia hepática el valor de AST sérica está aumentado (Latimer et al.), junto con la ALT. Los eritrocitos contienen AST. El aumento elevado de la AST puede ocurrir cuando hay hemólisis in vivo e in vitro, así la hemólisis no sea aparente (Latimer et al.). Por histopatología, el hígado se encon- 
traba con esteatosis severa, aumento de la actividad de las células de kupffer, cambios en los hepatocitos que preceden a la necrosis hepática como son picnosis, cariorrexis, cariolisis; presencia de bilirrubina en el parénquima hepático y en las venas portales. Esta bilirrubina proviene de la degradación de la hemoglobina cuando los macrófagos procesan eritrocitos degenerados, igualmente proviene del bazo. La porfirina, el pigmento hemo, es escindida y el hierro es liberado, produciéndose la bilirrubina tras una serie de reacciones de oxidorreducción en los lisosomas. La bilirrubina no conjugada es transportada en la sangre, ionicamente ligada a la albúmina, hacia el hígado. La bilirrubina no conjugada es tomada por los hepatocitos. El complejo albúmina-bilirrubina se disocia en la membrana plasmática del hepatocito, entrando la bilirrubina en la célula para ser conjugada, principalmente como glucurónido. La bilirrubina conjugada que es hidrosoluble, es secretada en los canalículos biliares y puede ser también excretada en la orina. Cuando la bilis alcanza el duodeno el diglucorónido es escindido y la bilirrubina es convertida a urobilinogeno por las bacterias (Cheville, 1994; Latimer et al.). Según Willard \& Tvedten (2004), la hiperbilirrubinemia es producida en enfermedades hemolíticas y enfermedades hepatobiliares. La bilirrubinuria puede estar ausente porque los riñones caninos conjugan la bilirrubina, pero es a menudo presente en insuficiencia hepática aguda. En el paciente no se tiene como referencia la presencia de bilirrubina en la orina y los valores de bilirrubina en suero, pero por histopatología se puede concluir que el hígado del paciente presentaba bilirrubina en el parénquima hepático, probablemente causada por la insuficiencia hepática aguda que produjo que no hubiera conjugación de la bilirrubina libre con el ácido glucurónido. Igualmente en los vasos portales se observó bilirrubina puesto que estos drenaron sangre proveniente del bazo, siendo éste el principal órgano de producción de bilirrubina. Esta bilirrubina entra en la corriente sanguínea, se une a la albúmina y es transportada al hígado. Al ser insoluble en agua no atraviesa el filtro glomerular renal y es procesada en el hígado, o si el hígado esta alterado, se acumula en la corriente sanguínea (Cheville; Latimer et al.). En el resto de órganos no hubo presencia de bilirrubina.

En el paciente se encontraron niveles séricos normales de ALT, SAP y globulina concordando con lo reportado por Willard \& Tvedten. En encefalopatías hepáticas y enfermedades hepáticas severas adquiridas (cirrosis), pueden estar normales los valores séricos de ALT y fosfatasa alcalina (SAP). En el paciente no se presentaron cambios, severos en el hígado como la cirrosis pero se evidenció por histopatología esteatosis severa y por cambios sugestivos de necrosis hepática, como lo son la picnosis, cariorrexis, cariolisis, lo cual indica daño en el citoplasma y núcleo, sin ruptura aún de la membrana celular, por lo cual los niveles de ALT están en rangos normales. La AST es una enzima tanto mitocondrial como citosólica. Los niveles de AST aumentan séricamente cuando hay una lesión celular muy severa (necrosis), donde se presenta liberación de las enzimas mitocondriales y citosólicas para realizar la auto digestión enzimática de la célula necrosada. La AST no es específica del hígado, se encuentra en otros tejidos. El aumento de la actividad de AST sérica usualmente es asociada con daño muscular o hepático. Aunque los niveles de AST en el paciente fueron elevados sugiriendo tanto daño muscular como hepático severos. Si fuera daño hepático se encontrarían niveles elevados tanto de ALT y AST, lo cual no ocurrió. Cuando hay daño muscular hay aumento de la CK y de la AST por lo tanto, antes de concluir que el aumento de la actividad de AST sea sólo el resultado de la enfermedad hepática se confirmó por valoración de la cretininquinasa $(\mathrm{CK})$ la necrosis muscular (Latimer et al.). En el paciente no se evaluó la CK, por lo cual no se puede aseverar que los valores elevados de la AST en él sean indicativos de daño muscular pero tampoco se puede descartar.

Se presentó en el paciente albúmina de 1,99 g/dl, es decir hipoalbuminemia, debida a la inanición proteica por la anorexia que presentó el animal, concordando con lo reportado con Latimer et al., donde la producción disminuida de albúmina es asociada con mala nutrición, mala absorción intestinal, preñez, lactación, insuficiencia pancreática exocrina, enfermedad crónica del hígado y caquexia asociada a neoplasia, que es la causa más probable en el paciente, puesto que poseía dos tipos de neoplasias malignas, como son el condrosarcoma mesenquimal grado 3 y el carcinosarcoma de glándula mamaria. Aunque Willard \& Ttvedten, reportan que cuando hay una hipoalbuminemia significante (ej. albúmina $<2,1 \mathrm{~g} / \mathrm{dl}$ ) nunca podría ser atribuida a mala nutrición, puesto que la toma deficiente de proteína muy raramente causa concentraciones de albúmina sérica menor que 2,1 g/dl, excepto cuando son animales jóvenes y éste no es el caso. Puede también presentarse hipoalbuminemia por la insuficiencia hepática crónica (Willard \& Tvedten) concordando con Latimer et al., que informan que en enfermedades hepáticas agudas se presenta normoalbuminemia, y que en fallas hepáticas crónicas o atrofias se presenta hipoalbuminemia. Esta hipoalbuminemia no es un indicador especiúfico de insuficiencia hepática. Generalmente, cuando hay insuficiencia hepática las concentraciones de las globulinas se disminuyen en forma leve. Cuando hay enfermedad hepática crónica la hipoalbuminemia es acompañada por hiperglobulinemia, no siendo el caso del paciente, en el cual los niveles séricos de globulina son normales. Por tanto, cual no es ésta la causa de la hipoalbuminemia. 
La hipoalbuminemia puede deberse a una nefropatía con pérdida de proteína por la enfermedad glomerular, evidenciándose en el paciente por histopatología la pérdida de la albúmina en la luz de los túbulos contorneados donde aparece de un tono rosa pálido. Aunque los niveles de globulina en el paciente están en rangos normales, todo coincide con lo reportado por Willard \& Tvedteny y Latimer et al., ya que la hipoalbuminemia con niveles de globulina normales o aumentados, sugiere disminución de la producción de la albúmina, aumento en la pérdida o secuestro. El aumento en la perdida de albúmina ocurre en enfermedades glomerulares. La albuminuria como resultado de glomerulopatías es raramente asociado con pérdida significativa de globulina.

Según Willard \& Tvedten, las causas para el decrecimiento del BUN son disminución en la producción (insuficiencia hepática, restricción en la proteína dietaria), aumento en la excreción (condiciones poliúricas, sobrehidratación o preñez tardía) o después del tratamiento con esteroides anabólicos (Latimer et al.). El decrecimiento del BUN puede ser un indicador de pruebas de funcionamiento hepático. Los mecanismos posibles que resultan en el decrecimiento de la concentración de BUN incluyen disminución en la producción de urea con la disminución de la función del ciclo de la urea hepática o disminución del catabolismo proteico y la disponibilidad para realizarse la síntesis de urea a partir del amonio. Así, animales jóvenes pueden tener valores de BUN disminuidos por el incremento de consumos de fluidos, incremento de la eliminación de orina y un alto estado anabólico por crecimiento rápido (Latimer et al.). En el paciente la disminución de los valores séricos del BUN es causada por la insuficiencia hepática, restricción en la proteína dietaria y excesiva producción del factor de necrosis tumoral a (FNTa), concordando con lo reportado por Willard \& Tvedten.

Los resultados de microbiología, fueron negativos a hongos y levaduras, existiendo presencia de escasos diplococos (Neisseria) y bacilos esporulados, que hacen parte de la flora bacteriana normal de la nariz; por lo tanto, no se evidencia infección.

Tanto en las neoplasias de la nariz y de la glándula mamaria se encontró una elevada celularidad de una población de células de estirpe conjuntiva con núcleo redondo u ovalado, citoplasma basófilo con finas vacuolas y dispuestas en voluminosos agregados celulares y rodeados por una matriz amorfa extra e intercelular eosinofílica, muy común en neoplasias de origen óseo/cartilaginoso, concordando con los reportes dados por De Buen de Arguero y Fernández et al.
La evaluación histopatológica del tumor primario en la región sinonasal reveló proliferación de condrocitos en una matriz cartilaginosa, zonas hemorrágicas, área anaplásica mixoide de condrosarcoma mesenquimal grado 3 , mostrando células con forma spindle o estrellada. La apariencia histopatológica de la metástasis pulmonar fue similar a la masa primaria encontrándose pleomorfismo celular, células con binucleación y con nucleolos, evidenciando la malignidad de la neoplasia. No se aprecian figuras mitóticas. Concordando con lo reportado por Nesi et al., 2000 y Romanucci et al. (2005), quienes caracterizan al condrosarcoma mesenquimal como una variante no común de condrosarcoma, típicamente compuesto de dos componentes característicos del tumor: islas cartilaginosas y cordones de células mesenquimales primitivas (o tejido conectivo pobremente diferenciado y áreas de matriz condroide o cartilaginosa (Salvador et al., 1971; Martinek et al., 2006, Ohta et al.). En el parénquima pulmonar adyacente a los nódulos neoplásicos de condrosarcoma puede apreciarse otro tipo de neoplasia que ha hecho metástasis al pulmón, el carcinosarcoma de glándula mamaria, compuesto por células fusiformes tipo spindle conformando la porción sarcomatosa y componentes adenocarcinomatoso de glándula mamaria, con múltiples focos hemorrágicos. No se aprecian figuras mitóticas. Concordando con lo reportado por Meuten, donde las metástasis son mixtas, sarcomatosas o carcinomatosas. Se reconoce como un carcinoma complejo.

Según Anderson et al. (1969), Brodey et al. (1974), Madarame et al. (1998), Sullivan, 1960, Martinek et al., es la región esternocostal el lugar más frecuente en originarse el condrosarcoma mesenquimal en ovejas y perros, aunque en el presente caso, el origen del tumor fue el cartílago de la región sinonasal y la distribución de las metástasis pulmonares fue consistente con la diseminación hematógena. Este es el primer reporte de condrosarcoma mesenquimal sinonasal tipo III en perros y de carcinosarcoma de glándula mamaria en un mismo animal.

\section{AGRADECIMIENTOS}

Agradecemos a la Clínica Veterinaria y al Laboratorio Clínico de la Universidad de los Llanos, al Sr. Carlos Isaquita Técnico del Laboratorio de Ictiopatología de la Universidad de los Llanos, al Laboratorio de Histopatología de la Universidad de los Llanos y a los estudiantes de noveno semestre de Medicina Veterinaria y Zootecnia del primer ciclo de 2006, de la Universidad de los Llanos. 
ROQUE, R. A. I.; OCHOA, A. J. E. \& NARVAEZ, C. J. Sinunasal mesenchymal chondrosarcoma grade 3 and mammary gland carcinosarcoma of canine. Clinical and histopathology study. Int. J. Morphol., 26(4):861-875, 2008.

SUMMARY: To the Veterinary Clinic of the Universidad de los Llanos, come a 9 years old Chow Chow female canine, whose consultation reason was a bilateral epistaxis occurred 4 months ago, sudden loss of the vision and a mass in the nasal region of $2 \mathrm{~cm}$ of diameter approximately, according to the report of the owner, the mass showed up 1 month the day of the consultation. To the clinical exam they were the following abnormal discoveries. Hirsute hair, opaque, presented a subdermic mass approximately in the nasal region superior of $2 \mathrm{~cm}$. diameter that grew to $5 \mathrm{~cm}$. diameter after 1 month of the consultation, located in the nasal region superior and zigomatic region, of hard consistency, the animal had dysnea, bilateral mydriasis, the bilateral corneal reflection was negative, increase of the intraocular pressure of the right eye, the realized test of obstacles in the clinic was negative, that which showed us a blindness. Besides a complete clinical exploration and taking of the advantages of the cytology, she was carried out an aspired with fine needle of different areas of the masses so much neoplastic of the nose and of the region of the mammary gland, being obtained two types of samples. The cytology was evaluated to define origin of the tumors of the process. She was carried out biopsy for incision of the sinunosal region being diagnosed wicked tumor mesenchymal Chondrosarcoma sinunasal that commits bone. After having carried out the autopsy they took samples for histopathology. Being diagnosed mesenchymal chondrosarcoma sinunasal grade 3 , with metastasis to lung, and a carcinosarcoma of mammary gland.

\section{KEY WORDS : Canine; Chondrosarcoma sinunasal; Carcinosarcoma of mammary gland.}

\section{REFERENCIAS BIBLIOGRÁFICAS}

Anderson, L. J.; Sandison, A. T. \& Jarett, S. H. A British abattoir survey of tumours in cattle, sheep and pigs. Vet. Rec., 84:547-51, 1969.

Brodey, R. S.; Misdorp, W.; Riser, W. H. \& van der Heul, R. O. Canine skeletal chondrosarcoma: a clinicopathologic study of 35 cases. J. Am. Vet. Med. Assoc., 165:68-78, 1974.

Brodey, R. S.; Saber, R. M. \& Medway, W. Canine bone neoplasms. J. Am. Vet. Med. Assoc., 143:471,1963.

Carlyle, T.; Duncan, R. \& King, N. Veterinary Pathology. $6 \mathrm{t}^{\mathrm{h}}$ Ed. Philadelphia, Williams \& Wilkins, 1997.

Cheville, N. Introducción a la Anatomia Patológica General Veterinaria. Zaragoza, Editorial Acribia, 1994.

De Buen De Arguero, N. Citología Diagnóstica Veterinaria. Mexico, El Manual Moderno, 2001. p.146.

Doxey, D. L. Patología Clínica y Procedimientos de diagnostico en veterinaria. México, Editorial El Manual Moderno, 1983.

Fernández, C.; Jiménez, J. \& Aguilar, A. Citología de un tumor orbitario en un perro con exoftalmo compatible con un origen óseo. AMVAC, 10:28, 2005.

Giraldo, G.; Aranzazu, D.; Rodríguez, B.; Perez, M. \& Ramirez, M. Caracterización de las regiones organizadoras nucleolares coloreadas con Plata (AgNORs) en tumores mamarios caninos. Rev. Col. Cienc. Pec., 16:339, 2003.

Goldschmidt, H. \& Thrall, D. Malignant bone tumors in the dog. In: Newton, C. D. \& Nunamaker, D. (ED). Textbook of small Animal Orthopedics, Philadelphia, Lippincott, 1985. p.887.

Hahn, K. A.; McGavin, M. D. \& Adams, W. H. Bilateral renal metastases of nasal chondrosarcoma in a dog. Vet. Pathol., 34:352-5, 1997.

Latimer, K.; Mahaffey, E. \& Prasse, K. Duncan And Prasse's Veterinary Laboratory Medicine. Clinical Pathology. $4^{\text {th }}$ Ed. Iowa, Blackell Publishing, 2003.

Ling, G. V.; Morgan, J. P. \& Pool, R. R. Primary bone tumors in the dog: a combined clinical, radiographic and histologic approach to early diagnosis. J. Am. Vet. Med. Assoc., 165:55-67, 1974.

Madarame, H.; Itoh, H.; Yoshida, S.; Sakonju, I.; Takase, K. \& Hasegawa, Y. Canine mesenchymal chondrosarcoma of the ribs. J. Vet. Med. Sci., 60:975-9, 1998.

Martinek, B.; Bago, Z.; Flöck, M.; Hochsteiner, W.; Schilcher, F. \& Kofler, J. Chondrosarcoma in a simmental cow: Clinical, ultrasonographic, radiographic and pathological findings. Vet. J., 172:181-4, 2006.

Meuten, D. Tumors in Domestic Animals. $4^{\mathrm{er}}$. Ed. Iowa, Blackwell Publishing, 2002. 
Misdorp, W.; Else, R.; Hellmen, E. \& Lipscomb, T. P. Histological classification of mamary tumors of the dog and the cat. Armed Forces Institute of Pathology (U.S.).; American Registry of Pathology.; WHO Collaborating Center for Comparative Oncology. Washington, D.C., Armed Forces Institute of Pathology, 1999.

Nesi, G.; Pedemonte, E. \& Gori, F. Extraskeletal mesenchymal chondrosarcoma involving the heart: report of a case. Ital. Heart J., 1:435-7, 2000.

Newton, C. \& Siemering, G. Skeletal diseases. In: Ettinger, S. Textbook of veterinary internal medicine. Philadelphia, Saunders, 1983. p.2236.

Ohta, G.; Sakai, H.; Kachi, S.; Hirata, A.; Yonemaru, K.; Kitajima, A.; Yanai, T. \& Masegi, T. Assessment of Proliferative Potentials of Canine Osteosarcomas and Chondrosarcomas by MIB-1 Immunohistochemistry and Bromodeoxyuridine Incorporation. J. Comp. Path., 131:18-27, 2004.2

Robinson, W. \& Huxtable, C. Principios de Clinicopatología Médica Veterinaria. Zaragoza, Editorial Acribia, 1993.

Romanucci, M.; Bongiovanni, L.; Petrizzi, L. \& Della Salda L. Cutaneous extraskeletal mesenchymal chondrosarcoma in a cat. Vet. Dermatol., 16:121-4, 2005.

Salvador, A. H.; Beabout, J. W. \& Dahlin, D. C. Mesenchymal chondrosarcoma--observations on 30 new cases. Cancer, 28:605-15, 1971.

Sorenmo, K. Canine mammary gland tumors. Vet. Clin. North Am. Small Anim. Pract., 33:573-96, 2003.

Stayler, M.; Boosinger, T. R.; Pool, R. R.; Dammrich, K.; Misdorp, W. \& Larsen, S. Histological classification of bone and joint tumors of domestic animals. Armed Forces Institute of Pathology (U.S.).; American Registry of Pathology.; WHO Collaborating Center for Comparative Oncology. Washington, D.C., Armed Forces Institute of Pathology, 1994.

Sullivan, D. J. Cartilaginous tumours (chondroma and chondrosarcoma) in animals. Am. J. Vet. Res., 21:5315,1960 .

Theilen, G. W. \& Madewell, B. R. Veterinary cancer medicine. Philadelphia, Lea \& Febiger, 1979. 436p.

Willard, M. \& Tvedten, H. Small animal clinical diagnosis by laboratory methods. $4^{\text {th }}$ edition. Philadelphia, Elsevier, 2004.
World Health Organization International. Histological Classification of Mammary Tumors. Histological classification of mamary tumors of the dog and the cat. Med. J. Aust., 2:282-4, 1999.

Yildiz, F.; Gurel, A.; Yesildere, T. \& Ozer, K. Frontal chondrosarcoma in a cat. J. Vet. Sci., 4:193-4, 2003.

Dirección para correspondencia:

Prof. Julieta Esperanza Ochoa Amaya

Escuela de Medicina Veterinaria y Zootecnia

Facultad de Ciencias Agropecuarias y Recursos Naturales

Universidad de los Llanos

Villavicencio- Meta

COLOMBIA

E-mail: julietaeochoa@yahoo.es Julieta.ochoa@gmail.com

Recibido : 18-01-2008

Aceptado: 22-08-2008 
